\title{
Formação em saúde bucal e Clínica Ampliada: por uma discussão dos currículos de graduação
}

Brunna Rodrigues Machado dos Santos Bastos*; André Serra Clara*; Graciela Soares Fonsêca**; Fabiana Schneider Pires***; Carolina Rogel de Souza****; Carlos Botazzo*****

* Estudante de graduação, Faculdade de Odontologia da Universidade de São Paulo (FO-USP)

** Doutora, Docente da Universidade Federal da Fronteira Sul (UFFS), campus Chapecó

*** Doutora, Docente da Faculdade de Odontologia da Universidade Federal do Rio Grande do Sul (FO-UFRGS)

**** Doutoranda, Faculdade de Saúde Pública da Universidade de São Paulo (FSP-USP)

***** Doutor, Docente da Faculdade de Saúde Pública da Universidade de São Paulo (FSP-USP)

Recebido em 31/08/2017. Aprovado em 17/12/2017.

\section{RESUMO}

Na perspectiva de compreender percursos de formação e suas interfaces com os processos de trabalho no Sistema Único de Saúde (SUS), este artigo objetiva analisar as experiências vividas por estudantes de Odontologia em um estágio extracurricular no serviço de saúde no município de São Paulo. Tratase de estudo descritivo-exploratório de abordagem qualitativa, cujos sujeitos foram três estudantes de graduação em Odontologia, inseridos em um estágio em Clínica Ampliada que registraram suas experiências em diários de pesquisa. O material coletado foi trabalhado por análise de conteúdo temática. No período de maio a dezembro de 2015, foram atendidos - na Clínica Ampliada de saúde bucal da Unidade Básica de Saúde (UBS) - em média, 16 usuários por estagiário, número aproximado à quantidade de pacientes que um aluno de Odontologia da mesma Instituição de Educação Superior (IES) comumente atende durante sua graduação. A partir do conteúdo dos diários dos estagiários, percebe-se a existência de uma forte dissociação entre as vivências dos estudantes no espaço da pesquisa e suas experiências nos ambulatórios da IES. Apesar de passada mais de uma década desde a homologação das Diretrizes Curriculares Nacionais (DCN) para os cursos da área da saúde, e dos esforços para mudar o perfil profissional, persiste o distanciamento entre conteúdos e abordagens da graduação em saúde e os processos de trabalho no SUS. Por certo, o desafio reside também na efetividade da integração curricular, na diversificação de cenários de aprendizagem e na articulação com o SUS. As experiências vividas pelos estagiários revelam as diferenças profundas e arraigadas da prática odontológica nos cenários de ensino e no SUS.

Descritores: Saúde Bucal. Odontologia. Integração Docente Assistencial. 


\section{INTRODUÇÃO}

A formação de trabalhadores com competências para o enfrentamento da realidade sócio epidemiológica do Brasil constitui-se em um dos grandes desafios para a consolidação do Sistema Único de Saúde (SUS) ${ }^{1}$, pois permanece marcada pela fragmentação do conhecimento, reforçando a visão biologicista para as práticas de saúde.

A formação em Odontologia, a partir das Diretrizes Curriculares Nacionais $(\mathrm{DCN})^{2}$, de modo geral e por meio de alterações dos projetos pedagógicos dos cursos ${ }^{3}$, vem buscando valorizar perfis de egressos capazes de oferecer atenção integral humanizada, aptos ao trabalho em equipe e à melhor compreensão da realidade em que vive a população ${ }^{4}$, trazendo para a Odontologia a flexibilização do currículo, de modo a abranger e se adequar a realidade social local, formando um profissional generalista, com sensibilidade social e competência técnica. Tais diretrizes determinam a mudança do modelo rígido de currículo, com número de disciplinas e conteúdos delimitados, para um modelo com maior liberdade para a sua reorganização. Com isso, as questões de currículo, que há muito já não são um tema exclusivo dos especialistas em educação, estão novamente em pauta nas discussões da área da saúde ${ }^{5,6}$.

No entanto, permanece a formação tradicional em saúde, baseada na organização disciplinar e nas especialidades, conduzindo ao estudo fragmentado dos problemas de saúde das pessoas e da sociedade, levando à formação de especialistas que não conseguem lidar com as totalidades ou com realidades complexas ${ }^{7}$. Esta formação acadêmica do cirurgião-dentista dedicada a maior valorização das atividades curativas e inclinada ao desenvolvimento técnico-científico, traduziu-se em um processo com poucas discussões éticas, muito dependente de tecnologias produzidas e cultuadas pela indústria de insumos e medicamentos. É fato que por estruturar-se com currículos acadêmicos divididos em micro disciplinas, focados na doença e não no cuidado, muitas questões foram negligenciadas, inclusive sociais e culturais.

A crescente abertura de cursos de graduação no Brasil e a saturação do mercado de trabalho, principalmente nos grandes centros urbanos, fizeram com que o sistema liberal de assistência privada começasse a se desestabilizar $^{2,8}$. Em contrapartida, a partir da implementação da Política Nacional de Saúde Bucal (PNSB) ${ }^{9}$, a contratação de cirurgiõesdentistas para o trabalho no SUS aumentou expressivamente.

Nas diretrizes da PNSB, as linhas de cuidado em saúde emergem como proposta de reorientação das concepções e práticas para a assistência e o planejamento em saúde bucal, almejando um novo processo de trabalho?. Pautando-se na premissa de que cuidar é proporcionar bem-estar e assumir responsabilidades com o outro, ao se pensar em um modelo de atenção em saúde bucal pautado pelo cuidado, um grande deslocamento na prática clínica é proposto: deve-se centrar no usuário, em suas necessidades e suas demandas ${ }^{10,11}$.

$\mathrm{Na}$ perspectiva de compreender percursos de formação e suas interfaces com os processos de trabalho no SUS, este artigo objetiva analisar as experiências vividas por estudantes de Odontologia em um estágio extracurricular em um serviço de Atenção Primária à Saúde (APS) do Município de São Paulo. Este estágio compôs uma das metas do projeto de pesquisa "Inovação na produção do cuidado em saúde bucal: possibilidades de uma nova abordagem na clínica odontológica para o SUS", que pretendeu propor, desenvolver e avaliar novas tecnologias de cuidado em saúde bucal.

\section{PROCEDIMENTOS METODÓLOGICOS}

Estudo descritivo-exploratório com abordagem qualitativa, cujos participantes foram 
três estudantes de graduação em Odontologia de uma instituição pública de ensino superior.

Os estudantes foram inseridos na equipe do projeto de pesquisa realizando atendimentos semanais - em turnos de 04 horas - a usuários vinculados a uma Unidade Básica de Saúde (UBS) do Município de São Paulo, e participando de discussões teóricas - totalizando 08 horas de dedicação semanal - entre os meses de maio e dezembro de 2015.

Nos atendimentos clínicos, a abordagem consistiu em ouvir o usuário e suas queixas, buscando compreender sua condição de saúde, social e de vida, estruturando a prática por um método clínico centrado no sujeito. Objetivou-se desenvolver uma compreensão das características de cada usuário, nas suas necessidades, singularidades e desejos para construir, com o usuário e não para o usuário, um projeto terapêutico singularizado.

A primeira etapa do atendimento, compreendida como anamnese, era realizada em ambiente não odontológico, ou seja, o usuário era ouvido numa sala comum da unidade de saúde (consultório médico ou de enfermagem), com mesa e cadeiras. Acomodados, usuário e profissional de saúde (cirurgião-dentista e estagiário, na maior parte das vezes) sentados de frente um para o outro, a consulta iniciava com uma conversa sobre a saúde, os motivos que o levaram a procurar pelo serviço, com escuta de suas narrativas, de sua condição de vida, suas queixas e condições bucais.

Na construção de uma Clínica Ampliada de saúde bucal na UBS cenário do estágio, a rotina de atendimento proposta pelos pesquisadores ao gestor da unidade previa o uso de tecnologias leves $^{12}$ como dispositivo para viabilizar o acolhimento e o vínculo do usuário ao serviço e à equipe de pesquisa. A equipe responsabilizouse pela agenda de atendimentos no ambulatório de saúde bucal no período já descrito. Todas as informações da anamnese eram registradas no prontuário do usuário. $\mathrm{Na}$ sequência, eram realizadas as intervenções clínicas pactuadas entre o usuário e a equipe que o atendia, sobretudo os procedimentos que guardavam relação com estados ou motivações mais claramente apontadas pelo usuário.

Os estagiários realizaram o registro reflexivo de suas práticas em diários de pesquisa. Nesse contexto, a utilização do diário de pesquisa permitiu a expressão de impressões, observações e avaliações e, por circularem no tempo e no espaço, foram objetos de autorreflexão, que também encorajou os estudantes, no sentido de mobilizá-los para uma busca pessoal voltada aos aspectos educacional, cognitivo e profissional ${ }^{13}$. Ao material escrito e produzido pelos estudantes, procedeu-se análise de conteúdo com a categorização dos temas ${ }^{14}$.

O projeto de pesquisa foi aprovado pelo Comitê de Ética em Pesquisa da instituição de ensino envolvida, por meio do parecer 501.0692014.

\section{RESULTADOS E DISCUSSÃO}

No período de maio a dezembro de 2015, foram atendidos - na Clínica Ampliada de saúde bucal da UBS - 135 usuários agendados para primeira consulta e 175 usuários nos atendimentos de retorno pós-procedimentos. Estes números indicam uma média de 1,54 retornos por usuário. Neste período, foram realizados 145 procedimentos clínicos, sendo a média de procedimentos odontológicos por período de atendimento (04 horas) de 7,25. Durante a vigência do estágio, os estudantes atenderam, em média, 16 usuários cada um, número aproximado à quantidade que um aluno de Odontologia da mesma Instituição de Educação Superior (IES) comumente atende durante sua graduação. Em geral, era necessário apenas 1 ou 2 consultas de retorno para 
finalização dos procedimentos que constituíam o projeto terapêutico singularizado de cada usuário, dentro do escopo e condições técnicas da APS. Muitas vezes, a equipe e os estagiários percebiam-se ultrapassando e renormalizando os protocolos da APS ${ }^{15,16}$.

A partir do conteúdo dos diários dos estagiários, percebe-se a existência de uma forte dissociação entre as vivências dos estudantes no espaço da pesquisa e suas experiências nos ambulatórios da IES. O quadro a seguir ilustra as principais diferenças identificadas pelo material analisado entre a atuação dos acadêmicos na UBS e nas atividades desenvolvidas nas clínicas da IES.

Quadro 1: As principais diferenças entre o formato do atendimento na UBS e no ambulatório da IES

\begin{tabular}{|c|c|c|}
\hline Tema & $\begin{array}{l}\text { Experiência clínica no } \\
\text { estágio na UBS }\end{array}$ & Experiência clínica na IES \\
\hline Acesso & Universal & $\begin{array}{c}\text { Triagem pelas necessidades das } \\
\text { disciplinas }\end{array}$ \\
\hline Modelo de atendimento & $\begin{array}{c}\text { Integralidade } \\
\text { Cuidado em saúde } \\
\text { Escuta qualificada e } \\
\text { acolhimento }\end{array}$ & $\begin{array}{c}\text { Centramento dentário } \\
\text { Tecnicista }\end{array}$ \\
\hline Anamnese & $\begin{array}{c}\text { Diálogo livre } \\
\text { Ambiente não odontológico } \\
\text { Anamnese coletiva eventual }\end{array}$ & $\begin{array}{c}\text { Perguntas objetivas } \\
\text { Cadeira odontológica } \\
\text { Anamnese coletiva ausente }\end{array}$ \\
\hline Projeto Terapêutico & $\begin{array}{c}\text { Singularizado } \\
\text { Tratamento conservador }\end{array}$ & $\begin{array}{c}\text { Odontocentrado } \\
\text { Tratamento invasivo }\end{array}$ \\
\hline Relação profissional-usuário & Horizontal & Vertical \\
\hline Aparato tecnológico & $\begin{array}{l}\text { Predomínio de tecnologias } \\
\text { leves }\end{array}$ & $\begin{array}{l}\text { Predomínio de tecnologias } \\
\text { duras }\end{array}$ \\
\hline Forma de registro & Prontuário Único & $\begin{array}{c}\text { Ficha } \\
\text { Odontológica/Odontograma }\end{array}$ \\
\hline Discussão de caso na equipe & Rotina & Eventual \\
\hline $\begin{array}{c}\text { Aproximação com políticas } \\
\text { públicas }\end{array}$ & $\begin{array}{c}\text { Teoria e prática } \\
\text { Reflexão-ação-reflexão }\end{array}$ & Discussão teórica \\
\hline
\end{tabular}

A primeira categoria emersa dos diários dos estagiários refere-se ao acesso dos usuários atendidos. Pelas características da UBS $-\mathrm{e}$, por conseguinte do SUS - na unidade, o acesso é disponibilizado a todos que procuraram atendimento não permitindo, como acontece frequentemente nas clínicas da faculdade, uma seleção de usuários de acordo com as necessidades de aprendizagem do estudante. Em contraposição, na IES, os estudantes iniciam o atendimento a usuários previamente triados de acordo com os requisitos pré-definidos de cada disciplina.

Destaca-se, destas observações, grande 
separação entre o ensino e a prática nos serviços de saúde: ao passo que a universalidade garante o acesso a todos os cidadãos, reiterando a saúde como direito de todos ${ }^{17}$, na IES, a organização do acesso se dá pelas demandas de cada disciplina criando uma pseudo-realidade, adequada às necessidades de adestramento técnico dos estudantes ${ }^{18}$.

Ao encontrar "pessoas reais", com perfis complexos, com sofrimento e doenças mentais, agravos crônicos, em situação de vulnerabilidade e queixas variadas, os estagiários sentiram-se inseguros e desconfortáveis para a abordagem clínica. Ocorre que, diferente do ambulatório da IES em que a necessidade é voltada para o procedimento técnico, na Clínica Ampliada que propunha o projeto de pesquisa, a técnica odontológica deveria compor um projeto terapêutico singularizado, com o usuário no centro do cuidado, estimulando um complexo exercício de reflexão sobre a prática clínica.

A este respeito, vale transcrever excertos dos diários dos estagiários, aqui designados com nomes de flores:

Prazer, meu nome é ansiedade! E ansiedade seria a palavra ideal que melhor me descreveria logo no início do meu dia - o dia em que seria o meu primeiro atendimento no programa - o primeiro atendimento fora da clínica da [nome da Faculdade], fora da supervisão do professor da disciplina a cada inspiração e expiração realizada, fora dos padrões "[nome da Faculdade]" de atendimento, sem ter o paciente perfeito triado pelo professor da disciplina, sem saber antes mesmo de o paciente se sentar na cadeira os procedimentos odontológicos que serão realizados clínica de dentística: restaurações; clínica de periodontia: raspagem supra e subgenvival; e assim por diante. Mas não desta vez, desta vez sabia que seria diferente, sabia que o meu paciente era uma pessoa, e como todas as pessoas um ser imperfeito, que poderia ter problemas de hipertensão, diabetes, depressão, entre diversos outros agravantes de sua saúde geral, mas o que mais me assustava era não saber, pela primeira vez, quais procedimentos clínicos que realizaria em meu paciente e isso me deixava extremamente ansiosa (Rosa).

[...] foi como um primeiro dia de aula com a ansiedade, dúvida se eu daria conta do atendimento, de que forma eu conseguiria me "despir" da clínica moldada pela graduação e realizar o atendimento na perspectiva da Clínica Ampliada (Cravo).

Durante o atendimento, passado os primeiros 10 minutos, consegui controlar melhor a ansiedade era uma explosão de sentimentos, dúvidas, como se seria capaz de realizar fora da faculdade ou sua "pseudo proteção" mesmo sendo um procedimento simples que já realizei diversas vezes também me vi perdido na disposição dos equipamentos, me remetendo ao quanto somos "enquadrados" na graduação no olhar para o paciente, a forma e protocolo de atendimento, a disposição dos materiais e organização de bancada (Cravo).

Com relação ao modelo de atendimento clínico, na UBS, os estagiários experienciaram o cuidado em saúde com foco na integralidade, voltado para o acolhimento e resolução das queixas apresentadas pelos usuários. Como a anamnese constituía-se pela escuta qualificada das narrativas da vida do usuário, havia um proposital deslocamento do inquérito sobre a cavidade bucal, que produziu, tanto na equipe do projeto quanto nos estagiários e nos usuários, um 
novo olhar sobre a prática em saúde bucal. Não eram raras as discussões pós atendimento que analisavam o quanto de saúde bucal cabia na Clínica Ampliada e o quanto de vida, de reflexão e afirmação de $\mathrm{si}^{19}$ era produzido em cada atendimento/encontro na clínica.

Sobre a proposta de inovação na produção do cuidado, também se destaca o uso da anamnese coletiva - uma atividade realizada em grupo (com até doze participantes), em que percepções e experiências de vida e de saúde (também bucal) eram compartilhadas em roda, permitindo o acolhimento dos usuários e sua consequente vinculação à equipe e aos demais usuários ${ }^{11}$.

Por meio de uma escuta qualificada, o caso clínico era constituído durante a anamnese permitindo que os estagiários percebessem que o planejamento focado na cárie dentária e/ou outras afecções buco-dentárias, definidas $a$ priori, como comumente ocorre no ambulatório da IES, não responde satisfatoriamente às necessidades colocadas pelos usuários ${ }^{20}$.

Apesar da insegurança inicial, os estagiários passaram a ressignificar o adoecimento bucal, compreendendo a determinação social do processo saúde-doença, e buscando formas de atuação coerente com as demandas encontradas no sentido de respondêlas satisfatoriamente.

Hoje aprendi mais do que nunca em todos os anos na Faculdade. A Paciente [...] chega com a queixa principal que precisa confeccionar mais uma prótese total (ela já havia perdido várias próteses), eu já estava julgando-a mentalmente como irresponsável e achando tudo aquilo um absurdo, já pensava como que seria na Faculdade, no qual o Professor falaria em bom som que esta seria a última vez que confeccionaria a PT, eis então que a paciente abre na anamnese individual que ela era bipolar e em seus quadros de crises, saia correndo pelada pela rua, no momento me senti a pessoa mais sortuda do mundo por não ter expressado qualquer pensamento que tive, pois quem era eu para dar "bronca" numa situação dessa? Refleti completamente durante todo o resto do dia (Rosa).

Dos diversos casos clínicos, a constituição da História clínica talvez foi talvez foi o que me chamou mais atenção pois tivemos dois pacientes com problemas psiquiátricos como uma senhora de 71 anos, esquizofrênica que relata ter perdido a PT superior em um surto em que saiu pelada na rua (relata não tomar mais os remédios, por não querer), outro paciente com depressão que abriu a vida inteira na anamnese $e$ relatava ter $N$ problemas bucais (no exame clínico só constatou a necessidade de uma profilaxia e uma restauração $M O$ em molar - ou seja parece um caso de carência). Uma paciente de trinta e poucos anos que relata uma história pesada familiar, está se tratando com a psicóloga e “ fugiu" do Rio Grande do Norte trazendo uma filha de 6 anos que abandonou a escola (parece um caso de violência familiar e uso de drogas, aparentava estar impaciente) [...]. Bom, fica claro [...] como a condição bucal está intimamente relacionada ao sofrimento ao longo da vida" (Cravo).

Observa-se, no interior das faculdades, uma clínica fragmentada que analisa e trata a lesão de cárie, frequentemente desarticulada da clínica de periodontia que, por sua vez não encontra ligação com a clínica das lesões de 
tecidos moles, e por este trajeto continua e perpetua um fazer em saúde bucal que é duplamente insuficiente: ora por ser estritamente odontocentrado, ora por se 'multidividirem' em especialidades que também não se articulam entre si para compor o diagnóstico do caso clínico. Percebe-se uma prática deficiente, pois não há articulação dos diagnósticos bucais com as condições sistêmicas (biológicas) dos usuários e constantemente desaparecem os fatores sociais e mesmo psíquicos no entendimento e na condução do processo saúde-doença ${ }^{21}$.

Considerando que para a construção do modo de cuidar em saúde importa entender que o sofrimento humano torna o sujeito um usuário em busca de cuidado e é deste sofrer que surge a demanda por serviços de saúde ${ }^{22}$, torna-se possível cumprir o passo fundamental da produção do cuidado integral em saúde: exercer uma Clínica Ampliada ${ }^{11}$.

Ao "encaixotar" os usuários em determinadas características, nas conversas orientadas por "fichas", o encontro terapêutico é empobrecido e reduzido e as informações repassadas não são ressignificadas, traduzindo-se no cumprimento de uma tarefa de modo maquinal e automático ${ }^{21}$.

$\mathrm{Na}$ escuta qualificada realizada pelos estagiários, o usuário falava de si e de sua vida, atribuindo significados aos relatos. A experiência com a elaboração desse tipo de proposta desconstruiu, nos estágiários, a visão odontocentrada dos planos de tratamento usualmente elaborados na IES.

A segunda paciente havia passado já com o colega, e me foi passado que seria uma restauração Classe IV em resina composta no 12. De imediato, sem ver a paciente, pedi para a preceptora anestésico, espátula $n$ 1, sistema adesivo, resina A3 e A3,5, putz, que ato falho! Quando estava passando a xilocaína na paciente, a outra preceptora chegou e me perguntou o que iria fazer, mostrei a restauração e ela logo perguntou: - E a paciente pediu anestesia? Caraca meu, modo automático estava ligado, quando a preceptora me perguntou, saí do modo automático e me dei conta de como eu estava pensando apenas no procedimento como na faculdade. Aquela restauração não precisava de anestesia para ser realizada, era pequena, mas como na faculdade um dos tópicos de avaliação é a aplicação de anestesia nem me questionei se era necessário fui logo no modo automático. Ato mais falho foi não ter empoderado a paciente e ter colocado para ela a escolha em receber ou não anestesia. Chateado! (Cravo).

No exame clínico, acabo por decidir institivamente o que será realizado na consulta, porém sou chamada a atenção ao me perguntarem se o paciente concordava com essa primeira etapa, eis que percebo que novamente esqueci do essencial, empoderar o paciente para que ele, juntamente comigo consiga definir o que é prioritário a ser tratado, entrando em acordo e dividindo responsabilidades. $O$ nível hierárquico proposto pela Universidade está mais incorporado institivamente em mim do que imaginava. Quase fiz igual a um quadro que vivenciei na graduação, no qual precisava fazer uma restauração em amálgama para "treinar" e foi decido entre as monitoras que seria o elemento X e que começaria justamente por ele, sem ao menos informar o paciente o que era essa tal de restauração de amálgama e se ele realmente queria este tipo de material. Em outro nível fiz a mesma coisa no estágio, ia implementar o que para mim 
era o melhor a se fazer, sem ao menos, perguntar para o paciente o que ele achava da situação. Grande lição apreendida neste dia (Rosa).

Acreditando que modelos hierárquicos e inflexíveis impostos à relação profissionalusuário dificultam o alcance da integralidade do cuidado em saúde ${ }^{22}$, buscou-se conformar essa relação de modo horizontal, com divisão das responsabilidades e empoderamento do usuário, estimulando-se a criação de um ambiente acolhedor na Clínica Ampliada.

Os estagiários fizeram referência a este ponto, conforme recorte de um dos diários:

Ainda acho incrível a anamnese individual. Conduzi uma apenas uma vez com a preceptora e gostei muito. Acho muito importante essa nossa abordagem com o paciente, seja na anamnese coletiva ou individual, ela me parece a porta de entrada para o cuidado. Sinto que o paciente não se sente na posição de paciente, uma posição muito delicada para algumas pessoas, a conversa rola de igual para igual, porém não deixamos de nos focar na saúde dele. E refletindo um pouco sobre o conceito de saúde, que não é mais só a ausência de doença: como, nos serviços de saúde nós aplicamos esse conceito? Vejo que os serviços ainda veem a saúde como apenas ausência de doença, esquecem de todos os outros fatores que a influenciam. Eé nessa hora que entra a questão do cuidado (ainda gosto de refletir sobre isso porque é tudo muito novo hehehe, e a própria palavra 'cuidado' fica ecoando na minha cabeça e eu fico pensando sobre sua profundidade e importância) (Margarida).

Dessa maneira, o vínculo é estabelecido e reforçado a cada encontro, a cada negociação terapêutica, como resultado do diálogo franco, da assunção de responsabilidades e da resolução das queixas e necessidades $^{22}$. $\mathrm{O}$ vínculo estabelecido entre o profissional e usuário foi um dos destaques na Clínica Ampliada realizada nesta pesquisa e os estagiários se surpreenderam com o comprometimento e corresponsabilização do usuário em relação ao tratamento.

Como expresso em outros estudos ${ }^{3,23}$, a formação profissional mantém-se centrada no fazer mercantilista, especialista e pouco direcionado a uma prática social, conformando uma odontologia imperativa, eximindo-se da inclusão do subjetivo do profissional na produção viva do cuidado em saúde ${ }^{23-25}$, uma vez que o aparato tecnológico focalizado pela IES refere-se às tecnologias duras, nas quais o estudante é condicionado a pensar sempre no tratamento de última geração, na odontologia de mercado e, a um só tempo, no proselitismo do consultório privado.

O ensino reproduz o modelo hegemônico, profissional-centrado, em que o outro é reduzido a um caso passível de ser enfrentado pela aplicação de tecnologias duras ou leve-duras, protocoladas, das quais o profissional - nesse caso, o estudante, sob orientação docente aporta o saber e o poder. Deveria buscar-se a vivência da atenção ao outro, de modo singular e centralizado, reduzindo a importância de fatores externos ao encontro como técnica, rotina, protocolo, profissão, instituição ou razão, gerando a compreensão da produção de saúde e não da prestação de assistência ${ }^{26}$.

Em situações adversas ou distintas daquelas existentes na IES, os futuros profissionais encontrarão dificuldades para cuidar e solucionar os problemas apresentados pelos usuários. No entanto, os estudantes que vivenciaram o estágio do projeto de pesquisa mostraram-se surpresos ao perceber que era possível resolver satisfatoriamente diversos 
problemas com intervenções mais conservadoras e acessíveis, sendo imprescindível - mais do que o aparato tecnológico duro - atributos ligados às tecnologias leves como sensibilidade, generosidade e empatia. Apesar das competências técnicas serem indispensáveis, o usuário não pode ser abordado apenas pelo uso de tecnologias duras. $\mathrm{O}$ atendimento do usuário inicia-se muito antes da intervenção clínica propriamente dita, inicia-se na anamnese, com o acolhimento, com o cuidado, com o saber ouvir.

Para exemplificar, seguem trechos dos diários dos estagiários que indicam o aprendizado de competências relacionais, a partir do uso de tecnologias leves, promovendo o cuidado sem, necessariamente, lançar mão do uso de tecnologias duras:

Neste dia atendi uma paciente que saiu feliz do atendimento, por eu ter oferecido uma possível alternativa de tratamento, que não incluía a exodontia de seus dentes anteriores 21 e 11, que apresentam mobilidade grau III, devido à força mastigatória, visto que a paciente oclui apenas com os incisivos e não apresenta nenhum contato posterior (Rosa).

A cada novo paciente que era chamado, me causava uma aflição, novamente no sentido de não saber onde estou lidando. $\mathrm{Na}$ queixa principal do paciente vou pensando nos milhares de procedimentos que temos disponíveis, porém nas intermináveis clínicas da Faculdade, com o serviço de laboratório e o professor para determinar no final do planejamento a conduta. Já na UBS esse "nivel" de tratamento não era possivel. Deparei-me com uma questão do que era realmente necessário para sanar com a queixa do paciente e percebi que tinha em mãos todos os materiais, não era necessário, nesta abordagem "mais conservadora" se me permita dizer, as altas tecnologias e serviço laboratorial (Rosa).

Os registros destacam os resultados práticos das intervenções propostas e pactuadas entre equipe e usuários, desenhadas a partir dos sinceros desejos por eles colocados, o que só pode surgir pelo vínculo que se estabeleceu entre os atores neste projeto de pesquisa. A cordialidade, a assunção de responsabilidades e a empatia foram o eixo condutor para que a técnica odontológica surgisse como uma utilidade e não como dispositivo de cuidado.

Outra colocação apontada nos diários analisados foi a prerrogativa de um processo de trabalho em saúde bucal que prescindisse do odontograma e adotasse o prontuário único (PU) da unidade de saúde para registrar e acessar as informações dos usuários. A perspectiva de incluir os registros do atendimento odontológico no PU casou desacomodação em setores da unidade de saúde, não apenas nos estagiários. A demanda por acesso aos PU pela equipe do projeto (a saúde bucal) precisou ser autorizada pelo Serviço de Arquivamento Médico e Estatística (SAME) da UBS e, muitas vezes, a administração da unidade não compreendia o motivo, dado o ineditismo deste fato - solicitar o PU - pois isso nunca antes ocorrera naquela unidade. Sabe-se que a formação do cirurgiãodentista não desenvolve habilidades para romper com seu isolamento e integrar-se a outros membros da equipe nas ações em saúde ${ }^{27}$. É fato que os processos de trabalho das equipes de saúde bucal permanecem isoladas, fragmentadas e muitas vezes desvinculadas do processo de trabalho da equipe de saúde, o que conduz a equipe de saúde bucal a raramente se inserir em práticas partilhadas com profissionais de outras áreas ${ }^{12,28,29}$.

Dentre as inovações propostas pelo projeto 
de pesquisa estava a 'desodontologização' do atendimento clínico em saúde bucal, viabilizando a realização de práticas cuidadoras ampliadas em detrimento do centramento dentário e dos $a$ priori presentes nas práticas tradicionais de odontologia. Ficou evidente o contraponto da proposta com a prática na IES, pois os estagiários identificaram a rigidez de cada disciplina clínica, que dispõe de uma ficha para o levantamento de informações, oferecendo opções para quem responde aos questionamentos, usualmente, com forte centramento dentário. Não há espaço para um diálogo livre que permita singularizar o atendimento, o que compromete a compreensão de cuidado reduzindo-o ao entendimento da realização de procedimentos técnicos.

Frisa-se, ainda, como um diferencial da experiência no projeto de pesquisa, a possibilidade de discussão do caso clínico com preceptores e coordenação do projeto e os demais membros da equipe. Para os estagiários, esse momento possibilitava o aprofundamento de reflexões que, por sua vez, gerava novas formas de atuação frente ao que lhes era apresentado. $\mathrm{O}$ trecho a seguir ilustra essa constatação:

Poder realizar a discussão (que julgo ser o momento mais importante dessa formação para abrir os olhos e mente para a nova forma de ver o atendimento) (Cravo).

Da mesma forma que descortinavam um novo mundo, os estagiários encontravam novos $\mathrm{e}$ persistentes entraves na formação, um afastamento entre $\mathrm{o}$ real (vivido nos atendimentos da unidade de saúde, com os usuários em sua gama de complexidades de saúde e de vida) e os atendimentos cotejados pela necessidade de formação: com 'manequins vivos' como os casos pré-selecionados pelos orientadores das diferentes disciplinas no curso de graduação.

Outro tema apontado no material do estudo refere-se a forma como, no ambiente acadêmico, a aproximação com as políticas públicas se dá, predominantemente, por abordagem teórica, sem muitas oportunidades de vivências reais. Desse modo, a compreensão da organização do trabalho em saúde bucal, sobretudo no SUS, é fragilizada. Os egressos dos cursos de saúde, quando se deparam com usuários reais no cotidiano do trabalho em saúde, apresentam dificuldades para compreender os processos de modo integral, o que justifica a predominância de abordagens centradas nos sinais e sintomas biológicos, fragmentadas e pouco resolutivas ${ }^{30}$.

Esta visão é favorecida e reforçada tanto pelas características da Odontologia de prática privada e mercantilista, como também pelos processos de formação da maioria dos cursos de graduação e pós-graduação ${ }^{31}$. Conceitualmente, compreende-se que o conjunto de experiências que estudantes vivem e as situações, os estímulos e os modelos que a escola oferece e que geram oportunidades particulares de aprendizagem compõe o currículo ${ }^{32}$. Feuerwerker e Almeida ${ }^{33}$ destacam que do currículo pode-se compreender a expressão do posicionamento do curso diante de seu papel social e de suas bases teóricas.

A formação deve pautar-se na realidade socioeconômica e cultural do país, dirigindo a atuação do egresso para a transformação da realidade em benefício da sociedade ${ }^{2}$. No entanto, um déficit na estrutura curricular aumenta a inadequação da formação dos profissionais de saúde nesta perspectiva e que tem levado à necessidade de requalificação profissional que pode ser constatada por meio dos recursos gastos pelo Ministério da Saúde em "qualificações"4. Finkler, Caetano e Ramos 6 destacam também o desafio da preparação mais realista dos acadêmicos para a atuação no mercado de trabalho já que características do passado ainda são adotadas como referência no processo de socialização profissional em 
Odontologia.

A experiência de estágio do projeto "Inovação na produção do cuidado em saúde bucal: possibilidades de uma nova abordagem na clínica odontológica para o SUS" permitiu que os estudantes conhecessem os processos de trabalho no seu cotidiano, aprendendo no ciclo açãoreflexão-ação, discutindo as vivências com os profissionais que acompanharam o estágio e buscando conhecimentos teóricos para subsidiar o vivido. Além de encontrarem situações clínicas complexas, experimentaram inovações na produção do cuidado em saúde e deslocaram-se da seara técnico-científica para adentrar o universo relacional/comunicacional, de escuta e de diálogo, na construção de percursos de cuidado nos quais as técnicas, como expressão de uma biopolítica, deram lugar aos atores do processo de trabalho em saúde: usuário e equipe de saúde.

\section{CONSIDERAÇÕES FINAIS}

Apesar de passada mais de uma década desde a homologação das DCN para os cursos da área da saúde, e dos esforços para mudar o perfil profissional, persiste o distanciamento concreto entre conteúdos e abordagens da graduação em saúde e os processos de trabalho no SUS. Por certo, o desafio reside também na efetividade da integração curricular, na diversificação de cenários de aprendizagem e na articulação com o SUS.

Se de certo modo a prática em Odontologia, historicamente, toma a boca como órgão fragmentado e destituído do corpo, por outro lado um "currículo oculto" nos cursos de graduação continua perpetuando o distanciamento entre a integralidade do cuidado e as técnicas odontológicas, criando uma fissura nas competências deste futuro profissional de saúde. Há clara necessidade de rupturas no processo engessado de formação na direção de um profissional generalista e com sensibilidade social, capaz de identificar não apenas sinais e sintomas clínicos, mas de desenvolver habilidades para a prática integral e humanizada, capaz de atender as demandas tanto singulares quanto coletivas.

As experiências vividas pelos estagiários revelam as diferenças, profundas e arraigadas da prática odontológica nos cenários de ensino da IES e no SUS. São diferenças inicialmente do modelo político-pedagógico que sustenta $o$ ensino no ambiente acadêmico e das competências e habilidades que se fazem intrinsecamente necessárias para o cuidado em saúde. Neste estudo retratamos as diferenças destes espaços - formação em Odontologia e o processo de trabalho em saúde bucal - a partir também de uma prática inovadora mesmo para a unidade de saúde (representando o modelo de saúde bucal do SUS). O cerne da discussão e reflexão proposta pelo estudo é, em especial, o distanciamento que uma formação essencialmente técnica e quase exclusivamente baseada em evidências científicas acaba por produzir nos jovens profissionais egressos dos cursos de graduação em Odontologia no país. Os diários dos estudantes que estagiaram neste projeto traduzem as angustias e aflições de grande parte dos recém-formados no Brasil. Rápidas mudanças ocorrem ao iniciarem o exercício profissional, e geralmente se deparam com a incongruência entre o aprendizado da universidade e a realidade encontrada nos ambientes de trabalho.

Considerando o material deste estudo, compreende-se que aos estudantes de Odontologia não são ensinados métodos de escuta e acolhimento, experiências para a criação de vínculo com o usuário e tampouco se relaciona o cuidado como não diretamente ligado à oferta de tecnologias duras, entre diversos outros fatores imprescindíveis a prática 
odontológica. Em múltiplas situações na formação são desconsideradas as subjetividades produzidas na condição do adoecimento, condição singular e fonte de informações para se organizar o atendimento clínico em qualquer esfera, tanto em serviços públicos de saúde quanto em práticas privadas.

É necessário mudar a estrutura curricular para que verdadeiramente se articulem os ciclos clínico e básico que ainda permanecem separados e organizados em disciplinas fragmentadas. Somente por meio de uma verdadeira integração do currículo, com a proposta de formação centrada no cuidado ao usuário, trazendo a excelência das técnicas odontológicas para o encontro das necessidades e desejos dos usuários que se poderia construir uma prática articuladora de diálogo entre atores e saberes da clínica, da saúde coletiva e da gestão.

Enquanto as Políticas de Saúde, o SUS e as DCN permanecerem dissociadas e refletirem esta realidade nas instituições acadêmicas - que, por sua vez, permanentemente enaltecem a alta tecnologia, o adestramento e a lógica da prática privada da profissão - o acolhimento e o vínculo com os usuários não serão priorizados. Os egressos devem apresentar competências profissionais e interpessoais para uma prática em saúde que se firme pela postura ética e política, como a capacidade de comunicação, criatividade, empatia e principalmente a habilidade de articular, em cada momento singular que o trabalho em saúde apresenta, a excelência técnica com as possibilidades e desejos singulares de cada usuário, tanto na perspectiva individual quanto coletiva.

\section{ABSTRACT \\ Formation in oral health and Extended General Practice: for a discussion of undergraduate curricula}

This study aimed to analyze the experiences of dental students on internship in an oral health public service in the city of São Paulo, Brazil. For this descriptive-exploratory study with a qualitative approach, the subjects were three undergraduate students in dentistry, inserted in a stage in an extended clinic that recorded their experiences in research journals. The collected material was worked by thematic content analysis. From May to December 2015, 16 patients were attended in the extended general practice, a higher number when compared with the number of patients that a dental student attends throughout their graduation. There is a real distance between contents and approaches of undergraduate health and the work processes in the public health service. The challenge also lies in the effectiveness of curricular integration, in the diversification of learning scenarios and articulation with public health. The experiences of trainees reveal the profound and deeply rooted differences in dental practice in school compared to the public service, in the Extended General Practice.

Descriptors: Extended General Practice. Curricular Guidelines. Oral Health.

\section{REFERÊNCIAS}

1. Moimaz SAS, Casotti CA, Saliba NA, Garbin CAS. Representação social de acadêmicos de odontologia sobre a área de Odontologia Social. Rev ABENO. 2006;6:145-9.

2. Brasil. Resolução CNE/CES 3/2002. Diário Oficial da União. Diretrizes Curriculares Nacionais do Curso de Graduação em Odontologia. Brasília. 4:10. [Acesso em 04 jan. 2017]. Disponível em: https://www.google.com.br/url?sa=t\&rct=j $\& \mathrm{q}=\& e s r c=s \&$ source $=$ web $\& \mathrm{~cd}=1 \& \mathrm{cad}=\mathrm{rja}$ $\underline{\text { \&uact }=8 \& \text { ved=0ahUKEwjg5vuC1srXAhX }}$ LnJAKHY4QAMcQFggsMAA\&url=http\% 3A\%2F\%2Fportal.mec.gov.br\%2Fcne $\% 2 \mathrm{Fa}$ rquivos $\% 2 \mathrm{Fpdf} \% 2 \mathrm{FCES032002.pdf \& usg=}$ AOvVaw35siyYd4hY4QYc24XMSR-X

3. Soares FF, Figueiredo CRV, Borges NCMB, Jordão RA, Freire MCM. Atuação da equipe de saúde bucal na estratégia saúde da família: análise dos estudos publicados no 
período de 2001 a 2008. Ciênc Saúde Coletiva. 2011;16(7):3169-80.

4. Morita MC, Kriger L. Mudanças nos cursos de Odontologia e a interação com o SUS. Rev ABENO. 2004; 4:17-21.

5. Ramos FRS. O discurso da bioética na formação do sujeito trabalhador da saúde. Trab Educ Saúde. 2007; 5(1):51-77.

6. Finkler M, Caetano JC, Ramos FRS. Modelos, mercado e poder: elementos do currículo oculto que se revelam na formação em odontologia. Trab Educ Saúde. 2014; 12(2): 343-61.

7. Brasil. Ministério da Saúde. Secretaria de Gestão do Trabalho e da Educação na Saúde. Caminhos para as mudanças da formação e desenvolvimento dos profissionais de Saúde: diretrizes para a ação política para assegurar educação permanente no SUS. Brasília, 2003. [Acesso em 15 de julho de 2017]. Disponível em: http://bvsms.saude. gov.br/bvs/publicacoes/politica2

8. Pezzato LM, L'Abbate S, Botazzo C. Produção de micropolíticas no processo de trabalho em saúde bucal: uma abordagem socioanalítica. Ciênc Saúde Coletiva. 2013;18(7):2095-04.

9. Brasil. Ministério da Saúde. Secretaria de Atenção à Saúde. Departamento de Atenção Básica. Coordenação Nacional de Saúde Bucal. Diretrizes da Política Nacional de Saúde Bucal. Brasília (DF), 2004. Acesso em 04 jan 2017]. Disponível em: http://dab.saude.gov.br/portaldab/pnsb.php

10. Botazzo C, Fonsêca GS, Pires FS, Souza CR, Junqueira SR, Pezzato LM. et al. Inovação na produção do cuidado em saúde bucal. Possibilidades de uma nova abordagem na clínica odontológica para o Sistema Único de Saúde. Relatório Técnico. São Paulo; 2015.

11. Pires FS, Botazzo C. Organização tecnológica do trabalho em saúde bucal no SUS: uma arqueologia da política nacional de saúde bucal. Saúde Soc. 2015; 24(1):27384.

12. Merhy EE. Saúde: a cartografia do trabalho vivo. São Paulo: Hucitec, 2002.

13. Waldow VR. Diários. In: Waldow VR. Estratégias de ensino na Enfermagem: enfoque no cuidado e no pensamento crítico. São Paulo: Ed. Vozes; 2005. p. 45-53.

14. Bardin, L. Análise de conteúdo. Lisboa, Edições 70, 1977.

15. Schwartz Y. Trabalho e uso de si. In: Schwartz Y, Durrive, L. (Org.). Trabalho e ergologia. Entrevistas sobre a atividade humana. Niterói: EduFF, 2007. p.191-206.

16. Trinquet $P$. Trabalho e Educação: o método ergológico. Rev HISTEDBR. 2010; : 93113.

17. Paim JS, Silva LMV. Universalidade, integralidade, equidade e SUS. BIS, Bol Inst Saúde. 2010; 12(2):109-14.

18. Fonsêca GS, Junqueira SR, Zilbovicius C, Araujo ME. Educação pelo trabalho: reorientando a formação de profissionais da saúde. Interface Comunic Saúde Educ. 2014; 18(50): 571-83.

19. Cunha EL. Entre o assujeitamento e afirmação de si. Cadernos de Psicanálise, SPCRJ. 2002;18(21):167-80.

20. Barros RS, Botazzo C. Subjetividade e clínica na atenção básica. Narrativas, histórias de vida e realidade social. Ciênc Saúde Colet. 2011;16(11):4337-48.

21. Fonsêca GS. Formação pela experiência: Revelando novas faces e rompendo os disfarces da odontologia 'in vitro' [tese]. São Paulo: Faculdade de Odontologia da Universidade de São Paulo; 2015.

22. Camargo Jr KR. Um ensaio sobre a (In) definição de integralidade. In: Pinheiro R, Mattos RA. (Org.). Construção da 
integralidade: cotidiano, saberes e práticas em saúde. Rio de Janeiro: Abrasco, 2003. p. 35-43.

23. Pezzato L. Encontros, instituições e sujeitos em análise: a alta pactuada em saúde bucal [tese]. Campinas: Faculdade de Ciências Médicas da Universidade Estadual de Campinas; 2009.

24. Santos NR. SUS, Política Pública de Estado: Seu desenvolvimento instituído e instituinte, o Direito Sanitário, a Governabilidade e a busca de saídas. Rio de Janeiro: Cebes, 2012. p. 71.

25. Zanetti CHG. A crise da Odontologia brasileira: as mudanças estruturais do mercado de serviços e o esgotamento do modo de regulação Curativo de Massa. Arq Odontol. 1999;1(6):232-9.

26. Ceccim RB, Merhy EE. Um agir micropolítico e pedagógico intenso: a humanização entre laços e perspectivas. Interface Comunic Saúde Educ. 2009; 13(1): 531-42.

27. Faccin D, Sebold R, Carcereri D.L. Processo de trabalho em saúde bucal: em busca de diferentes olhares para compreender e transformar a realidade. Ciênc Saúde Colet. 2010; 15(Suppl 1):1643-52.

28. Pimentel FC, Albuquerque PCD, Martelli PJDL, Souza WVD, Acioli RML. Characterization of the work process by oral health teams in municipalities in Pernambuco State, Brazil, according to population size: from community links to organization of clinical care. Cad Saúde Pública. 2012; 28(supl):146-57.
29. Teixeira MCD. A dimensão cuidadora do trabalho de equipe em saúde e sua contribuição para a odontologia. Ciênc Saúde Colet. 2006;11:45-51.

30. Ceccim RB, Carvalho YM. Ensino da saúde na integralidade: a educação dos profissionais de saúde no SUS. In: Pinheiro R, Ceccim RB, Mattos RA. Ensinar saúde: a integralidade e o SUS nos cursos de graduação na área da saúde. Rio de Janeiro: CEPESC-IMS/UERJ/ABRASCO; 2011. p. 69-92.

31. Toassi RFC, Souza JM, Baumgarten A, Rösing CK. Avaliação curricular na educação superior em Odontologia: discutindo as mudanças curriculares na formação em saúde no Brasil. Rev ABENO. 2012;12(2):170-7.

32. Galli A. Argentina: transformación curricular. Educación Médica y Salud. 1989; 23(4):344-53.

33. Feuerwerker LCM, Almeida M. Diretrizes curriculares e projetos pedagógicos: é tempo de ação! Rev Abeno. 2004; 4(1):14-6.

Correspondência para

Graciela Soares Fonsêca

e-mail: graciela.fonseca@uffs.edu.br

Rodovia BR 158 - Km 405

Bloco dos professores, sala 317

85301-970 Chapecó, SC 